\title{
Ginsenoside Rg5: Rk1 Exerts an Anti-obesity Effect on 3T3-L1 Cell Line by the Downregulation of PPAR $\gamma$ and CEBPa
}

\author{
Shakina Yesmin Simu 1, Sungeun Ahn ${ }^{2}$, Veronica Castro-Aceituno ${ }^{2}$, Deok-Chun Yang 1,2* \\ ${ }^{1}$ Graduate School of Biotechnology and Ginseng Bank, College of Life Sciences, Kyung Hee University, Yongin, Republic \\ of Korea. \\ ${ }^{2}$ Department of Oriental Medicinal Biotechnology, College of Life Sciences, Kyung Hee University, Yongin, Republic of \\ Korea. \\ *Corresponding author: Deok-Chun Yang, Department of Oriental Medicinal Materials and Processing, Graduate School of Biotechnology, College of \\ Life Science, Kyung Hee University, Yongin 449-701, Korea, Tel: +82-31-201-3837, Fax: +82-31-205-2688, E-mail: dcyang@khu.ac.kr
}

Received: 11 March 2016 Revised: 6 September 2017 Accepted: 18 September 2017; Published online: 29 December 2017

\begin{abstract}
Background: Obesity, a global health problem and a chronic disease, is associated with increased risk of developing type 2 diabetes and coronary heart diseases. A wide variety of natural remedies have been explored for their obesity treatment potential. Objective: The anti-adipogenic effect of ginsenoside Rg5:Rk1 (Rg5:Rk1) on 3T3-L1 mature adipocytes was investigated.

Materials and Methods: To elucidate the anti-obesity effect of $\operatorname{Rg} 5: \operatorname{Rk1}$, a mixture of protopanaxadiol type ginsenosides isolated from Panax ginseng Meyer in a 3T3-L1 adipocytes. In order to determine the anti-obesity effect of Rg5:Rk1, based on oil Red O Staining, triglyceride (TG) content in adipose cells was assessed. Furthermore, to elucidate the possible mechanism of Rg5:RK1 effect on lipid accumulation, mRNA and protein expression analyses of adipocyte markers such as STAT3, PPAR , CBEP $\alpha$ and ap2 were carried out.

Results: Rg5:Rk1 treatment showed an inhibition of lipid droplet accumulation and decrease of TG content. In addition, expression of STAT3, PPAR,$C E B P \alpha$ and ap 2 were decreased in a dose dependent manner. Similarly, the Rg5:Rk1 treatment reduced PPAR $\gamma$ and $\mathrm{CEBP} \alpha$ protein expression.

Conclusion: Rg5:Rk1 treatment exhibits anti-adipogenic activity by down-regulation of the STAT3/ PPARg/CEBPa

signaling pathway in 3T3-L1 adipocyte cell line.

Keywords: Adipogenesis, Ginsenosides, Obesity, PPAR- $\gamma 3$ T3-L1 cell.
\end{abstract}

\section{Background}

Obesity is considered a formost health problem and major risk factor for serious metabolic diseases such as diabetes, hypertension, heart disease, dyslipidemia, atherosclerosis, stroke, nonalcoholic fatty liver disease, neuronal injury and cancer (1-4). Moreover, obesity is defined as the imbalance between energy intake and expenditure that eventually leads to the accumulation of the excess amount of lipids (triglycerides) in a major cellular component adipocytes cell. Adipocytes play an important role in regulating lipid metabolism (5, 6). However, adipogenic differentiation is a complex process where pre-adipocytes are converted into adipocytes by regulating multiple signaling pathways. In this process, genes such as peroxisome proliferator- activated receptor gamma (PPAR $\gamma)$ and CCAATT enhancer binding proteins $(\mathrm{C} / \mathrm{EBP})$ are required to be transcribed for adipogenic differentiation. These so-called master regulators of adipogenesis control the expression of a variety of transcriptional factor to the formation of mature adipocytes (7). In addition to these transcription factors, recent studies have shown that the signal transducer and activator of transcription 3 (STAT3) and Jak2 (Janus kinase 2) play important roles in adipogenic differentiation by regulating PPAR $\gamma$ (8). Therefore, suppression of this process is essential to control adipogenesis. Many studies have aimed to reduce obesity by focusing on decreasing pre-adipocyte differentiation, inhibiting adipogenesis and increasing lipolysis (9). Although, a lot of drugs are available in 
market to treat obesity, but their prolong exposure may cause severe side effects. Thus, scientists are looking forward for new natural sources which have a strong potential of anti-adipogenic activity.

Natural compounds from different sources have gained attention owing to safety and extended efficacies in the development of pharmaceutical agents against obesity. Several natural plants, have been shown to exert anti-adipogenic through the modulation of different signaling pathway (10). Panax ginseng is one of the ancient beneficial medicinal plant has reported for the various pharmacological effect such as anti-cancer, anti-inflammation, antiobesity, bone osteoporosis, sexual enhancement and diabetics (11). Ginsenoside $\operatorname{Rg} 5: \operatorname{Rk} 1$ is a mixture of protopanaxadiol-type ginsenoside, isolated from $P$. ginseng root, via a nine-time repetitive steaming and drying process (black ginseng), and was shown to possess many biological effects such as osteoporosis and inflammation $(12,13)$. However, the effect of $\operatorname{Rg} 5: \operatorname{Rk} 1$ in adipogenesis and the related underlying mechanism have not yet been investigated.

\section{Objective}

In this study, the anti-adipogenic effect of ginsenoside Rg5:Rk1 was investigated. Cytotoxicity and lipid accumulation or TG content in 3T3-L1 mature adipocytes were evaluated. Furthermore, the ability of ginsenoside $\mathrm{Rg} 5: \mathrm{Rk} 1$ to reduce the expression of different adipogenic markers in 3T3-L1 mature adipocytes was assessed.

\section{Materials and Methods}

\subsection{Chemicals}

3T3-L1 fibroblast cells were purchased from the ATCC, American Type culture collection. The cells were cultured in Dulbecco's modified Eagle's medium containing $10 \%$ fetal bovine serum and $1 \%$ penicillin streptomycin $(\mathrm{P} / \mathrm{S})$. Cell culture media Dulbecco's modified Eagle's medium (DMEM) and newborn calf serum (BCS) was obtained from Welgene (Gyeongsangbuk-do, South Korea), the antibiotic solution was purchased from GeneDEPOT (Barker, TX, USA). Insulin, 3-isobutyl-1-methyxanthine (IBMX), dexamethasone were purchased from Wako (Tokyo, Japan), PPAR $\gamma$ (cat no: sc 7273, mouse monoclonal), CEBP $\alpha$ (cat no: sc-61) and Beta actin (cat no: sc-47778, mouse monoclonal) primary antibody were from Santa Cruz Biotechnology, Inc. (Dallas, TX, USA). The ginsenoside Rg5:Rk1 mixture (95\% purity) was obtained from Ginseng Genetic Resource Bank (Kyung Hee University, Korea) and dissolved in dimethyl sulfoxide (DMSO) and stored at $-20{ }^{\circ} \mathrm{C}$.

\subsection{Cell Culture and Differentiation of Adipocytes}

3T3-L1 fibroblast was grown and differentiated into the adipocyte. The cells were maintained in DMEM supplemented with $10 \% \mathrm{BCS}$ and $1 \%$ penicillinstreptomycin $(\mathrm{P} / \mathrm{S})$ (complete medium) at $37{ }^{\circ} \mathrm{C}$ in a $\mathrm{CO}_{2}$ incubator. Cells were plated at density $1 \times 10^{4}$ in a 24 well plate complete medium. Two or three days after confluency (day 0) of the cells were stimulated with differentiation medium (MDI) containing $1 \mu \mathrm{M}$ dexamethasone, $0.5 \mathrm{mM}$ IBMX, and $10 \mu \mathrm{g} \cdot \mathrm{mL}^{-1}$ insulin added into Complete media. After two days later, 3T3L1 cells were supplemented with insulin in complete media defined as differentiation medium (DM) in the presence or absence of ginsenoside Rg5:Rk1 and further incubated for additional 5-8 days. Approximately the day 8 adipocyte cell displayed the characteristic of the differentiated cell (with lipid droplet) under the microscope.

\subsection{Cytotoxicity Assay}

Cytotoxicity of ginsenoside $\operatorname{Rg} 5: \operatorname{Rk} 1$ was determined by the MTT assay. 3T3-L1 pre-adipocytes were seeded in a 96 well plate at a density of $1 \times 10^{4}$ cells/ well. After confluency ( $24 \mathrm{~h}$ incubation), the media was fully removed and the cells were treated with various concentrations (1-100 $\left.\mu \mathrm{g} \cdot \mathrm{mL}^{-1}\right)$ of ginsenoside $\mathrm{Rg} 5: \mathrm{Rk} 1$ for $72 \mathrm{~h}$. MTT assay solutions $(20 \mu \mathrm{L})$ were added to the treated cells to stain the pre-adipocyte cell. Cell viability was determined using an ELISA reader (Bio-Tek Instruments, Inc., Vinooski, VT, USA) at 570 $\mathrm{nm}$ as previously described (14).

\subsection{Oil Red O Staining and TG Content}

To investigate the excess lipid accumulation in adipocyte cell Oil red O (ORO) staining assay was performed. After differentiation of 3T3-L1 pre-adipocyte to mature adipocyte on day 8 , cells were washed with PBS and fixed with $3.7 \%(\mathrm{v} / \mathrm{v})$ formaldehyde for $1 \mathrm{~h}$. Cells were stained with $60 \%$ isopropanol in filtered ORO solution (6:4 of oil red stock solution: distilled water) for $30 \mathrm{~min}$. The excess stain was removed by washing with distilled water 3 to 4 times before observation under an inverted light microscope (Nikon Instruments, Melville, NJ, USA). For the quantitative determination of excess lipid (TG content) in adipocytes, ORO staining eluted with $100 \%$ isopropanol and the absorbance was measured at $520 \mathrm{~nm}$ using Synergy ${ }^{\mathrm{TM}} 2$ microplate reader (Bio-Tek Instruments, Inc., Vinooski, VT, USA). 


\subsection{RNA Isolation and RT-PCR}

Total RNA was extracted from differentiated 3T3-L1 on day 8 using TriZol LS reagents (Invitrogen, Carlsbad, CA, USA) according to manufacturer's protocol. First strand cDNA was synthesized with $1 \mu \mathrm{g}$ of total RNA by using Thermo Scientific cDNA synthesis kit (Onebio, Lithuania, EU) according to the protocol. The Reversetranscription polymerase chain reaction (RT-PCR) was performed on the cDNA using gene-specific primers (Table 1). For amplification of PPAR- $\gamma$ and STAT3 the PCR cycles $(31)$ were $94{ }^{\circ} \mathrm{C}$ for $40 \mathrm{~s} ; 58{ }^{\circ} \mathrm{C} ; 72{ }^{\circ} \mathrm{C}$ for 5 min. PCR amplicons were loaded in 1\% agarose gel for electrophoresis.

\subsection{Real-Time PCR}

The gene expression levels were analyzed by quantitative real-time RT-PCR using a real-time rotary analyzer (Rotor-Gene 6000; Corbet Life Science, Sydney, Australia). The reaction was performed by using SYBER $^{\circledR}$ Green SensiMix plus Master Mix (Quantace, England), with gene specific primers (Table 1). The thermo reaction $(10-14 \mu \mathrm{L})$ was contained $1-2$ $\mu \mathrm{g}$ of cDNA. Real-Time PCR was carried out for 40 cycles of $95{ }^{\circ} \mathrm{C}$ : $10 \mathrm{sec} ; 60{ }^{\circ} \mathrm{C}: 10 \mathrm{sec} ; 72{ }^{\circ} \mathrm{C}$ : $20 \mathrm{sec}$. $\beta$-actin was used as housekeeping gene to normalize the data (15).

\subsection{Western Blotting}

Cells were seeded in 6 well plate at a density of $1 \times 10^{4}$ and adipocyte differentiation was induced as described above with the presence or absence of ginsenoside $\mathrm{Rg} 5: \mathrm{Rk} 1$ at concentration of $100 \mu \mathrm{g} \cdot \mathrm{mL}^{-1}$. After differentiation on day 8, cells were rinsed twice with PBS and incubated with $2 \mathrm{X}$ sodium dodecyl sulfate (SDS) loading buffer containing $100 \mathrm{mM}$ Tris- $\mathrm{Cl}$ (pH 6.8), 4\% $(\mathrm{w} / \mathrm{v})$ SDS, $0.2 \%(\mathrm{w} / \mathrm{v})$ bromophenol blue, $20 \%(\mathrm{v} / \mathrm{v})$ glycerol and $200 \mathrm{mM} \beta$-mercaptoethanol for $5 \mathrm{~min}$ at $22{ }^{\circ} \mathrm{C}(17)$. Cell lysates were collected and denatured at $95{ }^{\circ} \mathrm{C}$ for $10 \mathrm{~min}$. Protein samples were loaded to $10 \%$ SDS-polyacrylamide gel and electrophoresed. The separated proteins were transferred to PVDF membrane (ATTO Corporation, Tokyo, Japan) at $100 \mathrm{~V}$ for $2 \mathrm{~h}$. Membranes were blocked with 5\% skimmed milk for 2 $\mathrm{h}$ and incubated with specific primary antibodies such as PPAR $\gamma, \mathrm{CEBP} \alpha$ (Santa Cruz Biotechnology, Inc) for $16 \mathrm{~h}$ at $4{ }^{\circ} \mathrm{C}$. The memberanes were washed 7 times with Tris-buffered saline and Tween 20 (TBST). The blot was probed by anti-rabbit secondary antibodies (Santa Cruz Biotechnology, Inc) for $2 \mathrm{~h}$ at $22^{\circ} \mathrm{C}$ and immuno-reactivity was detected through Enhanced Chemiluminescence system (Amersham Bioscience Inc., Piscataway, NJ, USA) and exposed to X-ray film (Fuji photo Film Co. Ltd Minato, Tokyo, Japan). Band densities were measured using ImageJ software (16).

\subsection{Statistical Analysis}

Statistical analysis was performed using GraphPad 6.04 software (La Jolla, CA). Data are expressed as means \pm standard error of mean (SEM) of three independent experiment. The statistical significance of the differences between values was evaluated by oneway ANOVA. Statistical significance was accepted at a level of $p \leq 0.05$.

\section{Results}

Effects of Ginsenoside Rg5:Rk1 on Cell Viability

Ginsenoside Rg5:Rk1 exerted no cytotoxic effect at

Table 1. Primers used for RT-PCR and quantative real-time RT-PCR.

\begin{tabular}{lll}
\hline Primer Name & Sequence & Tm ('C) \\
\hline \multirow{2}{*}{ PPAR- $\gamma$} & Forward: 5'-ATGGGTGAAACTCTGGGAGATT-3' & 58.4 \\
& Reverse: 5'-AGCTTCAATCGGATGGTTCTT-3' & 55.9 \\
\multirow{2}{*}{ CEBP $\alpha$} & Forward: 5'-TTCATGGAGAATGGGGGCAC-3' & 59.3 \\
& Reverse: 5'-TAGACGTGCACACTGCCATT-3' & 57.3 \\
\multirow{2}{*}{ STAT3 } & Forward: 5'-GCCACGT TGGTGTTTCATAATC-3' & 58.4 \\
& Reverse: 5'-TTCGAAGGTTGTGCTGATAGAG-3' & 58.4 \\
ap2 & Forward : 5'-AAAGACAGCTCCTCCTCGAAGGTT-3' & 66.7 \\
& Reverse: 5'-TGACCAAATCCCCATTTACGC-3' & 57.9 \\
$\beta$-actin & Forward:5'-ATGAAGTGTGACGTTACGC-3' & 52.94 \\
& Reverse: 5'-CCTAGAAGCATTTGCGGTGCAC-3' & 64.75 \\
\hline
\end{tabular}


concentration up to $100 \mu \mathrm{g} \cdot \mathrm{mL}^{-1}$ whereas more than 98\% cells were viable (Data not shown).

\subsection{Effect of Ginsenoside Rg5:Rk1 on Intracellular} Lipid Accumulation During Differentiation in 3T3-L1 Pre-adipocyte

The effect of $\operatorname{Rg} 5: R k 1$ was tested to determine if it can suppress adipogenesis differentiation in 3T3L1. Cells were incubated with adipocyte hormonal cocktail with the presence or absence of $\mathrm{Rg} 5: \mathrm{Rk} 1$ at different concentration. Inside fat droplet, formation was analyzed by ORO assay. As shown in Figure 1a, intracellular lipid accumulation reduced to $100 \mu \mathrm{g} \cdot \mathrm{mL}^{-1}$ compared with MDI-treated cells used as the positive control. In addition, TG content suppressed at same concentration (Fig. 1b).

\subsection{Effect of Ginsenoside Rg5:Rk1 on Adipogenic} Markers STAT3, PPAR , CEBP $\alpha$, ap 2

Adipocyte differentiation is inflicted by the master regulator PPAR $\gamma$ involved in triglyceride synthesis and pre-adipocyte to adipocytes. Therefore, 3T3-
L1 cells were differentiated into mature adipocyte in the presence/absence of ginsenoside $\operatorname{Rg} 5: \operatorname{Rk} 1$. The expression of adipocyte markers, STAT3, PPAR , $C E B P \alpha$, and ap2, were analyzed by both RT-PCR and qRT-PCR. STAT3, PPAR , CEBP $\alpha$, and ap2 were significantly suppressed in a dose-dependent manner (Figs. 2a-2d). RT-PCR data showed that the expression of STAT3 and PPAR $\gamma$ were significantly decreased by the treatment with ginsenoside $\mathrm{Rg} 5: \mathrm{Rk} 1$ at the 100 $\mu \mathrm{g} . \mathrm{mL}^{-1}$ Therefore, ginsenoside $\mathrm{Rg} 5: \mathrm{Rk} 1$ may have a natural anti-adipogenic compound.

\subsection{Inhibitory Effect of Ginsenoside Rg5:Rk1 on the} Expression of Adipogenic Protein Expression

The effect of Rg5:Rk1 (100 $\left.\mu \mathrm{g} . \mathrm{mL}^{-1}\right)$ on the expression of PPAR $\gamma$ and CEBP $\alpha$ involved in adipogenesis were examined. Western blot analysis revealed that a timedependent increase in the protein expression levels of PPAR $\gamma$ and CEBP $\alpha$ in 3T3-L1 pre-adipocytes induced by the treatment of MDI in positive control compared with control (cell culturing complete media containing $10 \%$ BCS, $1 \%$ penicillin streptomycin in DMEM).

a
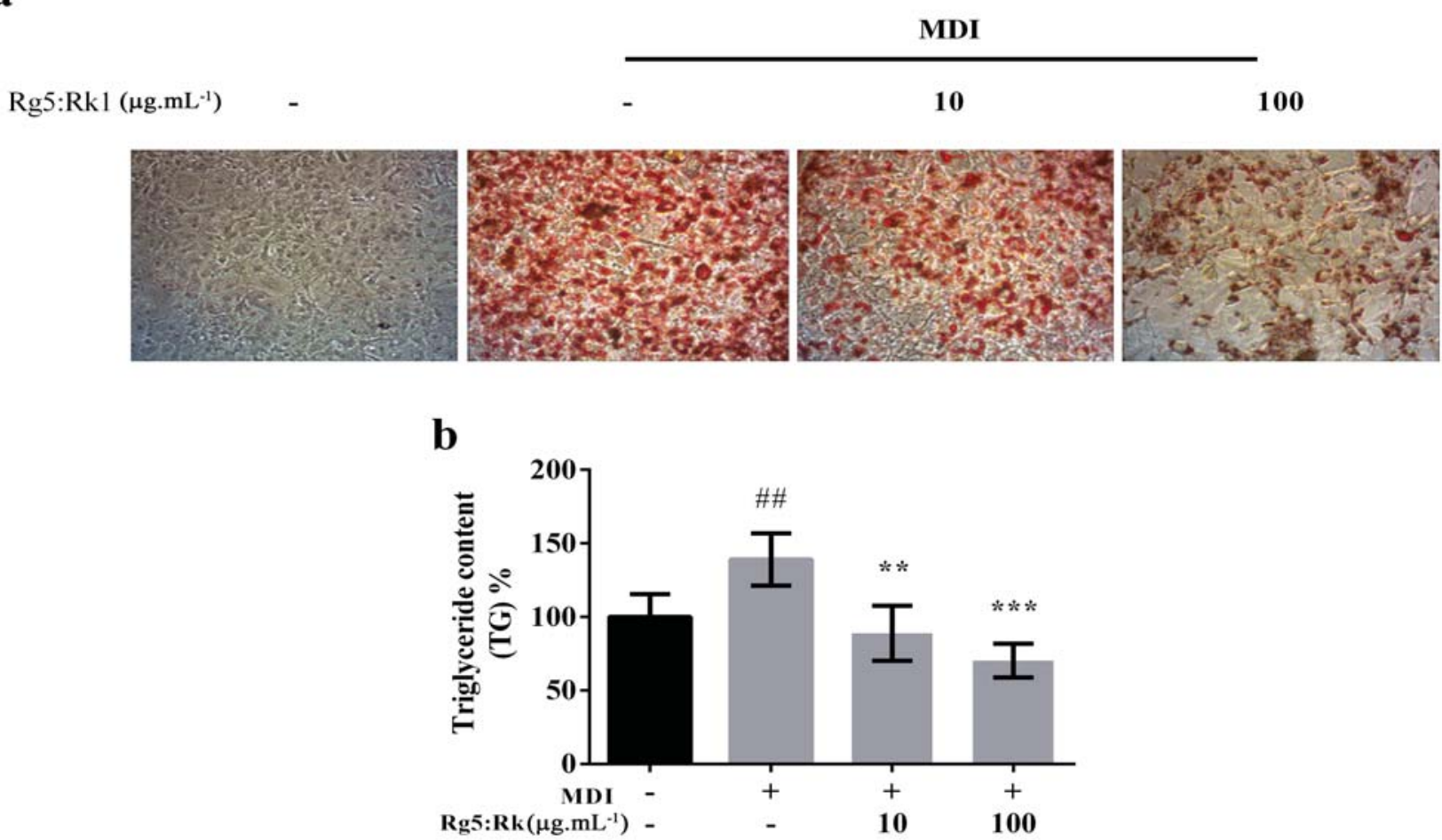

Figure 1. Effect of different concentration of ginsenoside $\mathrm{Rg} 5: \mathrm{Rk} 1$ on MDI-induced intracellular lipid accumulation in 3T3-L1 cells. The data shown are representatives of triplicate experiments. a: Demonstration of reduction of lipid accumulation in the cultured cells treated with ginsenoside $\operatorname{Rg} 5: \operatorname{RK} 1$, in a dose dependent manner.b: Comparative study of the Triglyceride content of the cells, treated with various amount of ginsenoside Rg5:RK1 Data are expressed as a percentage of control. \#\# (MDI treated cell) $p<0.01$ compare with control (absence of MDI and only given complete media) and **: $p<0.01 ; * * *: p<0.001$ versus MDI treated cell (differentiated cell). 
a

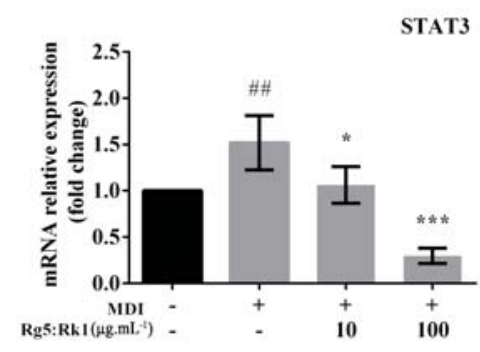

b

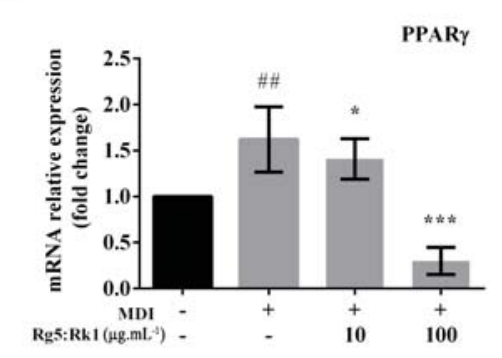

c

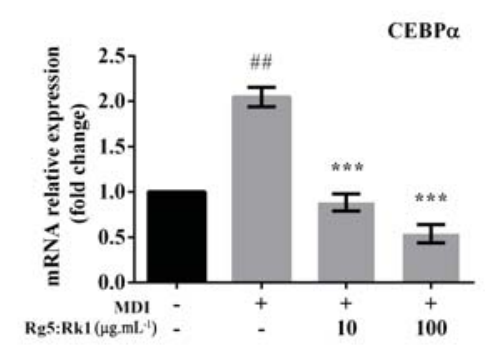

d

e
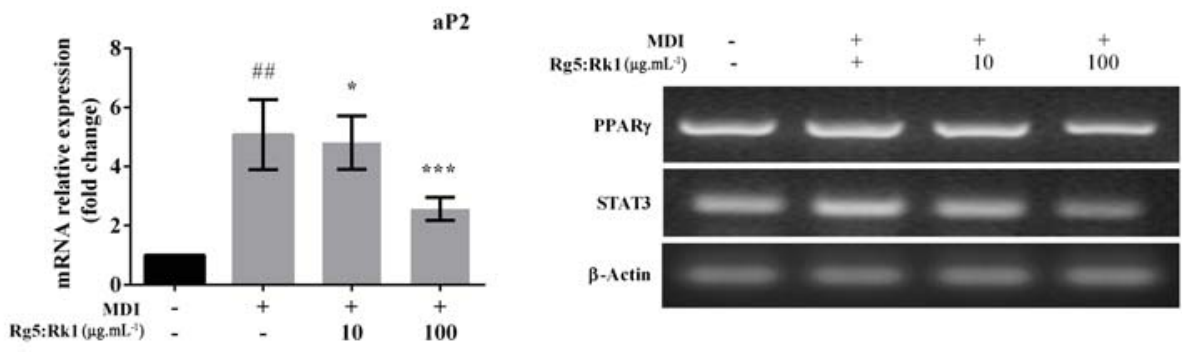

Figure 2. Effect of different concentration of ginsenoside Rg5:Rk1 on adipogenic transcriptional factors in 3T3-L1 adipocytes. Panels a-d: Th quantification of mRNA levels of STAT3, PPAR- $\gamma, C E B P \alpha$ and $a P 2$ genes were analyzed by qRT-PCT and normalized with $\beta$-actin as house keeping gene. Each value is expressed as the mean \pm standard error of three independent experiments. \#\# (MDI treated cell) $p<0.01$ compare with control (absence of MDI and only given complete media) and ${ }^{* *}: p<0.01 ; * *: p<0.001$ versus MDI treated cell (differentiated cell). Panel e: ThemRNA expression levels of PPAR- $\gamma$ and STAT3 by RT-PCR.

Whereas, treatment with $\operatorname{Rg} 5: \operatorname{Rk} 1$ (100 $\left.\mu \mathrm{g} \cdot \mathrm{mL}^{-1}\right)$ significantly inhibited the adipogenic protein expression such as PPAR $\gamma$ and CEBP $\alpha$ (Fig. 3).

\section{Discussion}

This study exposed for the first time the antiadipogenic effect of Rg5:Rk1 on the suppression of adipocyte differentiation through down-regulation of transcriptional factors such as PPARy, STAT3, aP2 and CEBP $\alpha$. Obesity is characterized at the cellular level by an increase in the number and size of adipocytes differentiated from fibroblastic pre-adipocytes to mature adipocytes in adipose tissue (18). Therefore, in order to interpret the potential anti-obesity effect and the mechanisms involved, the optimal working concentration of ginsenoside $\mathrm{Rg} 5: \mathrm{Rk} 1$ (Rg5:Rk1) was checked by evaluating its cytotoxicity on 3T3L1 pre-adipocytes. The result showed no significant cytotoxicity effect on 3T3-L1 up to $100 \mu \mathrm{g} \cdot \mathrm{mL}^{-1}$.

The development of fat cells from pre-adipocyte to mature adipocyte includes morphological changes, increase in cell numbers, expansion of cell size, expression of lipogenic enzyme and extensive accumulation of lipid droplet (19-21). In addition, accumulation of lipid droplet is an index of adipogenesis and it can be confirmed by ORO staining assay, which stains TGs and lipids in the mature adipocytes (22). So far, many studies have been reported that ginsenosides from Panax ginseng Meyer can reduce lipid accumulation in mature adipocyte by up and/ or down regulation of several signaling pathways at in vitro level (23-25). Our data showed that, Rg5:Rk1 effectively inhibited the adipogenic differentiation (reduced lipid droplet size) in 3T3-L1 pre-adipocytes at $100 \mu \mathrm{g} \cdot \mathrm{mL}^{-1}$ (Fig. 1a). Similarly, the TG content in mature adipocytes significantly reduced at $100 \mu \mathrm{g} . \mathrm{mL}^{-1}$ (Fig. 1b). Taken together, these data suggest that Rg5:Rk1 may have anti-adipogenic effect by reducing lipid droplet accumulation in 3T3-L1 mature adipocyte. Adipogenesis is the procession of the reflection of lipid accumulation of intracellular adipocytes through several signaling pathway by inducing overexpression of transcriptional factors such as STAT3, PPARy, CEBP $\alpha$ and ap2 $(26,27)$. Among them, PPARy and CEBP $\alpha$ are the major transcriptional factors regulating adipogenesis through modulating the expression of its target genes during early to middle stage of differentiation. Specially, 
a

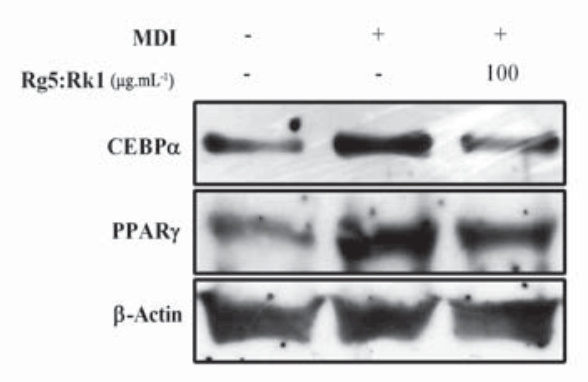

b

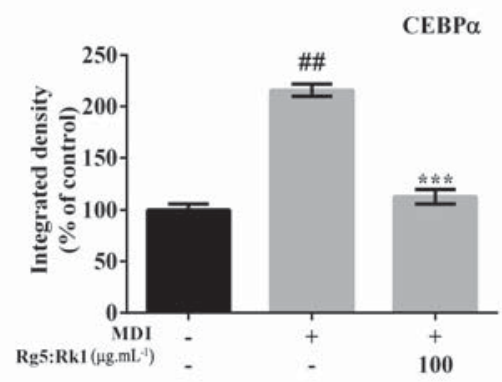

c

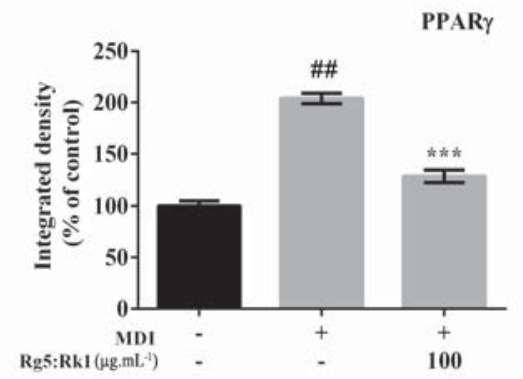

Figure 3. Protein expression levels of PPAR and CEBP were measured by western blotting (panel a), and integrated density was analyzed by ImageJ software (panels $b$ and c). Integrated density values were expressed as $\%$ of control. All experiment were performed in triplicate.

PPARy (peroxisome proliferator-activated receptorgamma) is highly expressed in adipocyte tissue compare with other tissues, and highly up-regulated when preadipocytes are converted into mature adipocyte (28). Besides, CEBP $\alpha$ (CCAAT/enhancer binding proteinalpha) primarily expressed in fat, liver and intestinal tissues, and is also reported as a key regulator of adipogenesis. Particularly, PPARy and CEBP $\alpha$ were reported to act as a cross-regulator on adipogenesis. These transcription factors control the adipogenic target gene such as ap2 (activating protein), which is directly implicated in lipogenic pathways in 3T3-L1 adipocytes (7). In addition, recent studies showed that signal transducer and activator of transcription 3 (STAT3) plays an imperative role in adipogenesis process (29). Furthermore, several studies have shown adipocyte differentiation is largely influenced by the expression of PPAR $\gamma$ and CEBP $\alpha$ (30-32). We found that transcript analysis of STAT3, PPARy, CEBP $\alpha$ and ap 2 genes, were significantly enhanced by the stimulation of hormone cocktail (MDI) once compared with undifferentiated cells. On the other hand, mRNA expression levels of these genes were decreased in differentiated cells after treatment with Rg5:Rk1 at $100 \mu \mathrm{g} \cdot \mathrm{mL}^{-1}$ (Figs. 2a-d). In addition, RT-PCR data showed that STAT3, PPARY genes were significantly blocked by the treatment of $\operatorname{Rg} 5: R k 1$ at concentration $100 \mu \mathrm{g} \cdot \mathrm{mL}^{-1}$ (Fig. 2e). Therefore, these results support that $\operatorname{Rg} 5: R k 1$ is capable of blocking adipogenic transcriptional factors. Subsequently, we investigated the protein expression level of major adipogenic proteins, PPARY and CEBP $\alpha$. It was found that $\operatorname{Rg} 5: \mathrm{Rk} 1$ significantly down-regulated protein expression levels at $100 \mu \mathrm{g} \cdot \mathrm{mL}^{-1}$ (Figs. 3a-c). Results indicates that expression of mRNA level of adipogenic genes and adipogenic proteins are similarly downregulated by the treatment of $\mathrm{Rg} 5: \mathrm{Rk} 1$ at 100 $\mu \mathrm{g} . \mathrm{mL}^{-1}$. Taken together, this data suggest that reduction of lipid accumulation in 3T3-11 cells after Rg5:Rk1 treatment might be regulated by down-regulation of the STAT3/ PPARy/CEBP $\alpha$ signaling pathway. However, this study is limited by the nature of pre-adipocytes growth cycle that remains to be elucidated.

In conclusion, our results demonstrate that Rg5:Rk1 from Panax ginseng Meyer efficiently inhibited adipogenesis in 3T3-L1 adipocytes by a significant reduction in intracellular lipid accumulation without induction of cytotoxicity in a dose-dependent manner. Furthermore, the inhibition of adipogenesis by Rg5:Rk1 might be mediated by major transcriptional activators PPAR $\gamma$ and CEBP $\alpha$. Therefore, ginsenoside Rg5:Rk1 may provide a possible therapeutic approach for the treatment of obesity.

\section{Acknowledgements}

This research was supported by iPET (313038-03-1SB010), Korea Institute of Planning and Evaluation for Technology in Food, Agriculture, Forestry and Fisheries, Republic of Korea. The ginseng sample used in this study was provided by Ginseng Bank Kyung Hee University.

\section{Conflict of Interest}

The authors have declared that there is no conflict of interest.

\section{References}

1. Giri S, Rattan R, Haq E, Khan M, Yasmin R, Won J-s, Key L, Singh AK, Singh I. AICAR inhibits adipocyte differentiation in 
3T3L1 and restores metabolic alterations in diet-induced obesity mice model. Nutr Metab. 2006;3(1):1. DOI: 10.1186/43-70753-31

2. Kopelman PG. Obesity as a medical problem. Nature. 2000;404(6778):635-43. DOI: 10.1038/35007508

3. Hursting SD, Hursting MJ. Growth Signals, Inflammation, and Vascular Perturbations Mechanistic Links Between Obesity, Metabolic Syndrome, and Cancer. Arterioscler Thromb Vasc Biol. 2012;32(8):1766-70. DOI:10.1161/ATVBAHA.111.241927

4. Choi JS, Kim J-H, Ali MY, Min B-S, Kim G-D, Jung HA. Coptis chinensis alkaloids exert anti-adipogenic activity on 3T3-L1 adipocytes by downregulating $C / E B P-\alpha$ and PPAR- $\gamma$. Fitoterapia. 2014;98:199-208. DOI:10.1016/j. fitote.2014.08.006

5. Frühbeck G, Gómez-Ambrosi J, Muruzábal FJ, Burrell MA. The adipocyte: a model for integration of endocrine and metabolic signaling in energy metabolism regulation. $\mathrm{Am} \mathrm{J}$ Physiol Endocrinol Metab. 2001;0(6):E827-E47. DOI:10.1152/ ajpendo.2001.0.6.E827

6. Ahima RS, Flier JS. Adipose tissue as an endocrine organ. Trends Endocrinol Metab. 2000;11(8):327-32. DOI:10.1016/ S1043-2760(00)001-5

7. Rosen ED, Walkey CJ, Puigserver P, Spiegelman BM. Transcriptional regulation of adipogenesis. Genes Dev. 2000;14(11):13-307. DOI:10.1002/cphy.c160022

8. Wang D, Zhou Y, Lei W, Zhang K, Shi J, Hu Y, Shu G, Song J. Signal transducer and activator of transcription 3 (STAT3) regulates adipocyte differentiation via peroxisome-proliferatoractivated receptor $\gamma(P P A R \gamma)$. Biol Cell. 2010;102(1):1-12. DOI: 10.1042/BC20090070

9. Ono M, Fujimori K. Antiadipogenic effect of dietary apigenin through activation of AMPK in 3T3-L1 cells. J Agric Food Chem. 2011;59(24):13346-52. DOI: 10.1021/jf203490a

10. Yun JW. Possible anti-obesity therapeutics from nature-A review. Phytochemistry. 2010;71(14):1625-41. DOI:10.1016/j. phytochem.2010.07.011

11. Helmes S. Cancer prevention and therapeutics: Panax ginseng. Altern Med Rev. 2004;9(3):259-75.

12. Siddiqi MH, Siddiqi MZ, Kang S, Noh HY, Ahn S, Simu SY, Aziz MA, Sathishkumar N, Jiménez Pérez ZE, Yang DC. Inhibition of osteoclast differentiation by ginsenoside $\mathrm{Rg} 3$ in RAW264. 7 cells via RANKL, JNK and p38 MAPK pathways through a modulation of Cathepsin $\mathrm{K}$ : an in silico and in vitro study. Phytother Res. 20;29(9):16-94. DOI:10.1016/j. phytochem.2010.07.011

13. Ahn S, Siddiqi MH, Aceituno VC, Simu SY, Zhang J, Perez ZEJ, Kim Y-J, Yang D-C. Ginsenoside Rg5: Rk1 attenuates TNF- $\alpha$ / IFN- $\gamma$-induced production of thymus-and activation-regulated chemokine (TARC/CCL17) and LPS-induced NO production via downregulation of NF- $\kappa \mathrm{B} / \mathrm{p} 38$ MAPK/STAT1 signaling in human keratinocytes and macrophages. In Vitro Cell Dev Biol Anim. 2016;52(3):287-95. DOI: 10.1007/s11626-015-9983-y

14. Siddiqi MH, Siddiqi MZ, Ahn S, Kim YJ, Yang DC. Ginsenoside Rh1 induces mouse osteoblast growth and differentiation through the bone morphogenetic protein 2/runt-related gene 2 signalling pathway. J Pharm Pharmacol. 2014;66(12):1763-73.
DOI: $10.1111 /$ jphp. 12306

15. Ahn S, Siddiqi MH, Aceituno VC, Simu SY, Zhang J, Perez ZEJ, Kim Y-J, Yang D-C. Ginsenoside Rg5: Rk1 attenuates TNF- $\alpha /$ IFN- $\gamma$-induced production of thymus-and activationregulated chemokine (TARC/CCL17) and LPS-induced NO production via downregulation of NF- $\mathrm{BB} / \mathrm{p} 38$ MAPK/STAT1 signaling in human keratinocytes and macrophages. In Vitro Cellular \& Developmental Biology-Animal. 2015:1-9. DOI: 10.1007/s11626-015-9983-y

16. collines TJ. ImageJ for microscopy. Biotechniques, 2007 43(1)25-30. DOI: 10.2144/000112517.

17. Dubon MJ, Park KS. Substance P enhances the proliferation and migration potential of murine bone marrow-derived mesenchymal stem cell-like cell lines. Exp Ther Med. 2015;9(4):1185-91. DOI: 10.3892/etm.2015.2291

18. Prins JB, O'rahilly S. Regulation of adipose cell number in man. Clin Sci. 1997;92(1):3-11. DOI: 10.1042/cs0920003

19. Devlin MJ, Yanovski SZ, Wilson GT. Obesity: what mental health professionals need to know. Am J Psychiatry. 2000;157(6):854-66. DOI: 10.1176/appi.ajp.157.6.854

20. Fujioka K. Management of obesity as a chronic disease: nonpharmacologic, pharmacologic, and surgical options. Obes Res. 2002;10(S12):116S-23S. DOI: 10.1038/oby.2002.204

21. Choi H, Eo H, Park K, Jin M, Park E-J, Kim S-H, Park JE, Kim S. A water-soluble extract from Cucurbita moschata shows antiobesity effects by controlling lipid metabolism in a high fat dietinduced obesity mouse model. Biochem Biophys Res Commun. 2007;359(3):419-25. DOI:10.1016/j.bbrc.2007.05.107

22. Ramirez-Zacarias J, Castro-Munozledo F, Kuri-Harcuch W. Quantitation of adipose conversion and triglycerides by staining intracytoplasmic lipids with Oil red O. Histochemistry. 1992;97(6):493-7.

23. Park S, Ahn IS, Kwon DY, Ko BS, Jun WK. Ginsenosides $\mathrm{Rb} 1$ and $\mathrm{Rg} 1$ suppress triglyceride accumulation in 3T3L1 adipocytes and enhance $\beta$-cell insulin secretion and viability in Min6 cells via PKA-dependent pathways. Biosci Biotechnol Biochem. 2008;72(11):2815-23. DOI:10.1016/j. bbrc.2007.05.107

24. Hwang J-T, Kim S-H, Lee M-S, Kim SH, Yang H-J, Kim M-J, Kim H-S, Ha J, Kim MS, Kwon DY. Anti-obesity effects of ginsenoside $\mathrm{Rh} 2$ are associated with the activation of AMPK signaling pathway in 3T3-L1 adipocyte. Biochem Biophys Res Commun. 2007;364(4):1002-8. doi:10.1016/j.bbrc.2007.10.125

25. Siraj FM, Natarajan S, Huq MA, Kim YJ, Yang DC. Structural investigation of ginsenoside $\mathrm{R} f$ with $P P A R \gamma$ major transcriptional factor of adipogenesis and its impact on adipocyte. J Ginseng Res. 2015;39(2):141-7. DOI.org/10.1016/j.jgr.2014.10.002

26. Song N-J, Yoon H-J, Kim KH, Jung S-R, Jang W-S, Seo C-R, Lee YM, Kweon D-H, Hong J-W, Lee J-S. Butein is a novel anti-adipogenic compound. J Lipid Res. 2013;54(5):1385-96. DOI: 10.1194/jlr.M035576

27. Jacobson NG, Szabo SJ, Weber-Nordt RM, Zhong Z, Schreiber RD, Darnell J, Murphy KM. Interleukin 12 signaling in T helper type 1 (Th1) cells involves tyrosine phosphorylation of signal transducer and activator of transcription (Stat) 3 and Stat4. J Exp Med. 1995;181(5):1755-62. DOI: 10.1194/jlr.M035576 


\section{Simu SY et al.}

28. Farmer S. Regulation of $P P A R \gamma$ activity during adipogenesis. Int J Obes. 2005;29:S13-S6. DOI:10.1038/sj.ijo.0802907

29. Zhang K, Guo W, Yang Y, Wu J. JAK2/STAT3 pathway is involved in the early stage of adipogenesis through regulating C/EBP $\beta$ transcription. $J$ Cell Biochem. 2011;112(2):488-97. DOI: $10.1002 /$ jcb. 22936

30. Park HJ, Chung BY, Lee M-K, Song Y, Lee SS, Chu GM, Kang S-N, Song YM, Kim G-S, Cho J-H. Centipede grass exerts antiadipogenic activity through inhibition of $\mathrm{C} / \mathrm{EBP} \beta, \mathrm{C} / \mathrm{EBP} \alpha$, and $P P A R y$ expression and the AKT signaling pathway in 3T3-L1 adipocytes. BMC Complement Altern Med. 2012;12(1):1. DOI: 10.1186/1472-6882-12-230

31. Yang SJ, Park N-Y, Lim Y. Anti-adipogenic effect of mulberry leaf ethanol extract in 3T3-L1 adipocytes. Nutrition research and practice. 2014;8(6):613-7. DOI:10.4162/nrp.2014.8.6.613.

32. Rosen ED, Hsu C-H, Wang X, Sakai S, Freeman MW, Gonzalez FJ, Spiegelman BM. C/EBP $\alpha$ induces adipogenesis through PPAR : a unified pathway. Genes \& development. 2002;16(1):22-6. DOI:10.1101/gad.948702 